\title{
Gold nanodots self-assembled polyelectrolyte film as reusable catalyst for reduction of nitroaromatics
}

\author{
PERUMAL VISWANATHAN and RAMASAMY RAMARAJ* \\ School of Chemistry, Centre for Photoelectrochemistry, Madurai Kamaraj University, Madurai, \\ Tamilnadu 625 021, India \\ E-mail: ramarajr@yahoo.com
}

MS received 11 August 2017; revised 8 November 2017; accepted 9 November 2017; published online 1 February 2018

\begin{abstract}
Separation of homogeneous catalyst from the reaction mixture is a crucial and difficult process in any catalytic process. To address this issue, a new class of multifunctional catalyst in the form of film was developed using a facile approach to enjoy the advantages of homogeneous catalyst with the versatility of heterogeneous catalyst. To achieve the same, methionine-capped gold nanodots (AuNDs) were self-assembled on a cationic polyelectrolyte modified glass plate for the catalytic reduction of nitro functional groups in the presence of olefinic double bond at mild conditions. Separation of this reusable catalytic film from the reaction mixture is very simple and advantageous when compared to the currently available and conventional catalytic systems. Kinetics of nitro reduction was monitored using absorption spectroscopy and the product formation was confirmed by ${ }^{1} \mathrm{H}$ and ${ }^{13} \mathrm{CNMR}$ analyses. Prepared AuNDs catalyst was characterized using UV-Vis spectroscopy, X-ray photoelectron spectroscopy (XPS), X-ray diffraction (XRD), high-resolution transmission electron microscopy (HRTEM), cyclic voltammetry and atomic force microscopy (AFM) techniques.
\end{abstract}

Keywords. Methionine; Au nanodots; catalytic films; nitroaromatics reduction.

\section{Introduction}

Catalysis has been an inevitable field of chemical research ever since its utility was recognized by research laboratories and chemical industries. Heterogeneous catalysts have received a great amount of attention both from scientific and industrial perspectives. Since $90 \%$ of chemical manufacturing processes in industries rely on heterogeneous catalysis, it has a significant impact on world economy. ${ }^{1}$ Though heterogeneous catalytic systems were adopted by industries, these are not perfect for industries as these lead to high operating temperatures, low selectivity, environmental damage, uneconomical cost and a complex process is required for reactivation of the catalyst. Conversely, homogeneous catalytic systems offer high activity and selectivity at relatively mild conditions, but the primary limitation of this catalytic system is the separation of the catalyst from the reaction mixtures that is usually critical for an industrial process. These facts created pressure on the scientific community to invent alternate catalytic systems, which address

\footnotetext{
*For correspondence
}

the problems associated with energy and environment across the globe. Thus, a lot of attention has been given to the development of new catalysts that combine the practical advantages of conventional heterogeneous catalysts with the versatility of homogeneous catalysts. In recent years, the issues regarding science and technology of catalysis have been effectively addressed by nanoscience and great strides have been achieved through novel nanomaterial catalysts. ${ }^{2}$ In this regard, gold nanoparticles (NPs) have had a significant impact on catalysis and have widely been employed for various catalytic applications. ${ }^{3}$ Moreover, designing a single catalytic system for multi-purpose catalytic applications is also an impressive development, which often surpasses the conventional catalytic systems employed in industries and scientific laboratories.

Aromatic amines are widely employed in the synthesis of pharmaceuticals, polymers, dyes and cosmetics. Transition metal-catalysed reduction of nitroaromatics into their corresponding aromatic amines is the traditional method used to prepare these industrially important compounds. ${ }^{4} \mathrm{Pt}, \mathrm{Pd}, \mathrm{Au}, \mathrm{Ag}, \mathrm{Fe}_{3} \mathrm{O}_{4} @ \mathrm{Ni}$ and

Electronic supplementary material: The online version of this article (https://doi.org/10.1007/s12039-017-1405-0) contains supplementary material, which is available to authorized users. 
$\mathrm{Ni@Ag} \mathrm{NPs} \mathrm{are} \mathrm{the} \mathrm{few} \mathrm{reported} \mathrm{catalytic} \mathrm{materials} \mathrm{for}$ the reduction of nitroaromatics, but the major problems associated with these catalytic systems are high $\mathrm{H}_{2}$ pressures, longer reaction times, lower turnover numbers, recyclability and high reaction temperatures. ${ }^{5}$ Though the noble metal NPs-decorated magnetic metal oxides show the good activity and recyclability, preparation and preservation of these catalytic systems seem to be critical in practice. Hence, the designing of new catalytic systems with features like operational simplicity, simple hydrogen sources, efficient conversion with selectivity and low cost is beneficial for the industry and researchers.

In the present work, sub-5 nm methionine capped $\mathrm{Au}$ nanodots (AuNDs) were prepared and successfully self-assembled onto cationic polyelectrolyte, poly(acryl amide-co-diallyldimethylammoniumchloride) (PADA), a modified glass plate for the catalytic reduction of nitroaromatics. This AuNDs-modified glass plate was successfully re-used for catalytic reduction reactions. The prepared catalytic film was found to be stable for more than two months at room temperature. This opens up the possibility of commercialization of this catalytic system.

\section{Experimental}

\subsection{Materials and methods}

Chloroauric acid $\left(\mathrm{HAuCl}_{4}\right)$ and poly(acrylamide-codiallyldimethylammonium chloride) (PADA), were received from Sigma-Aldrich. DL-methionine, 4-nitrobenzoic acid and 4-nitroaniline were obtained from the SRL and all other chemicals with analytical grade were received from Merck. All glassware were thoroughly cleaned with aqua regia (1:3 $\mathrm{HNO}_{3} / \mathrm{HCl}$ v/v) (Caution: A qua regia is a powerful oxidizing agent and it should be handled with extreme care.) and rinsed extensively with distilled water before use. UV-Visible absorption spectra were recorded using Agilent Technologies 8453 spectrophotometer using a $1 \mathrm{~cm}$ path length quartz cell and the samples for absorption studies were prepared by diluting $0.6 \mathrm{~mL}$ of as-synthesized Au colloidal solution in $1.4 \mathrm{~mL}$ of water. High-resolution transmission electron microscopy (HRTEM) and selected area electron diffraction (SAED) analyses were conducted in a Technai instrument operated at 200 $\mathrm{kV}$. The specimen for the HRTEM analysis was prepared by dropping the colloidal solution onto carbon-coated copper grid, and then dried at room temperature. XPS studies were performed using ULVAC-PHI 5000 versa Probe instrument. XRD patterns were recorded with a Rigaku diffractometer using $\mathrm{Cu} \mathrm{K} \alpha$ radiation $(\lambda=1.54 \AA)$. NMR spectrum was recorded on Bruker $300 \mathrm{MHz}$ instrument using $\mathrm{CDCl}_{3}$ and DMSO as solvents and the chemical shift values are reported as $\delta$ values (ppm) with reference to tetramethylsilane (TMS).

\subsection{Preparation of methionine capped AuNDs}

$5 \mathrm{~mL}$ of $0.01 \mathrm{M}$ methionine was mixed with $4.8 \mathrm{~mL}$ water and $0.2 \mathrm{~mL}$ of $0.5 \mathrm{M} \mathrm{KOH}$ and stirred for $10 \mathrm{~min} .0 .1 \mathrm{~mL}$ of 0.1 $\mathrm{M} \mathrm{HAuCl}_{4}$ was added to the above solution and mixed well for $2 \mathrm{~min}$. To this stirring mixture, $0.6 \mathrm{~mL}$ of $0.05 \mathrm{M}$ ice-cold $\mathrm{NaBH}_{4}$ was added slowly and the stirring was continued for $3 \mathrm{~h}$ at room temperature. The immediate formation of brown color confirmed the successful formation of AuNDs.

By adopting the same procedure, $\mathrm{KOH}$ concentration was varied $(0,5,10,15$ and $20 \mathrm{mM})$ in the preparation of various AuNDs. A black precipitate was observed in the absence and in the presence of $20 \mathrm{mM}$ and above the concentration of $\mathrm{KOH}$. Moreover, 5, 10 and $15 \mathrm{mM} \mathrm{KOH}$ led to the formation of stable AuNDs and the AuNDs were represented as M-Au- $\mathrm{K}_{5}$, $\mathrm{M}-\mathrm{Au}-\mathrm{K}_{10}$ and $\mathrm{M}-\mathrm{Au}-\mathrm{K}_{15}$ (The subscripts 5, 10 and 15 denote the concentration of $\mathrm{KOH}$ used in the synthesis).

\subsection{Preparation of catalytic plate for nitroaromatic reduction}

AuNDs coated glass plates with the area of $1.2 \mathrm{~cm}^{2}(0.8 \mathrm{~cm} \times$ $1.5 \mathrm{~cm}$ ) were utilised for the catalytic test studies of reduction of 4-nitrophenol upon the addition of $\mathrm{NaBH}_{4}$. The protocol adopted for the fabrication of AuNDs modified glass plates is as follows: Initially, $86 \mu \mathrm{L}$ of $0.1 \%$ PADA was drop casted on the glass plate area of $1.2 \mathrm{~cm}^{2}$, and allowed to dry at room temperature for $3 \mathrm{~h}$. Then the PADA modified glass plate was dipped in methionine-capped AuNDs solutions for $90 \mathrm{~min}$ to obtain AuNDs self-assembled catalytic plates. For laboratory scale synthesis of functionalized anilines, glass plate with the area of $6.25 \mathrm{~cm}^{2}(2.5 \mathrm{~cm} \times 2.5 \mathrm{~cm})$ was modified with PADA and AuNDs. In this preparation, glass plates with the dimension of $2.5 \mathrm{~cm} \times 7.5 \mathrm{~cm}$ were taken and $450 \mu \mathrm{L}$ of PADA was drop casted on the glass plate area of $6.25 \mathrm{~cm}^{2}$ $(2.5 \mathrm{~cm} \times 2.5 \mathrm{~cm})$ and dried for $3 \mathrm{~h}$ and then dipped in AuNDs solution for 90 min to obtain the AuNPs self-assembled catalytic plates. Dipping time of more than $90 \mathrm{~min}$ does not improve the catalytic activity. Figure 1 shows the schematic representation of the preparation of catalytic films.

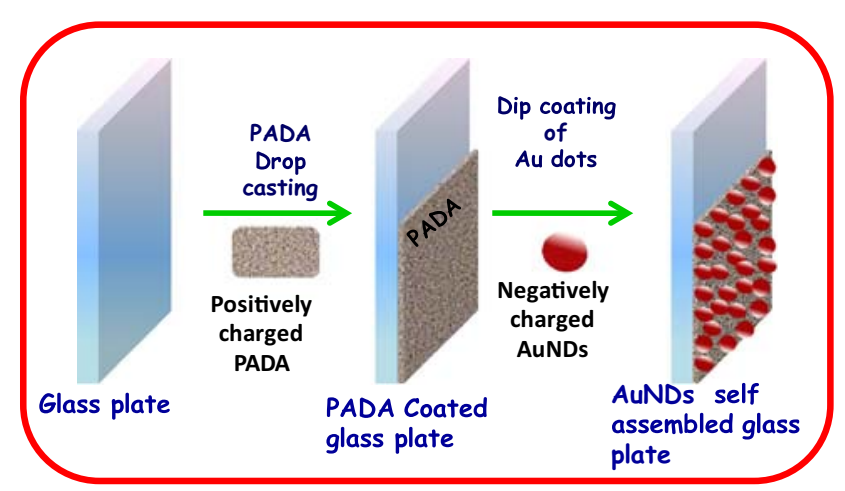

Figure 1. Schematic representation of the fabrication of AuNDs self-assembled onto PADA-modified glass plate. 


\subsection{Catalytic test reaction}

$0.1 \mathrm{~mL}$ of $2 \mathrm{mM}$ 4-nitrophenol solution was added to 1.4 $\mathrm{mL}$ water followed by $0.5 \mathrm{~mL}$ of $0.05 \mathrm{M} \mathrm{NaBH}_{4}$. To the above mixture, $25 \mu \mathrm{L}$ of as-synthesized AuNDs was added and the progress of reaction was monitored using UV-Vis spectroscopy. To test the catalytic activity of AuNDs modified glass plates (catalytic plates), to the above mentioned 4-nitrophenol and $\mathrm{NaBH}_{4}$ mixture, instead of AuNDs solution, catalytic plate of $1.2 \mathrm{~cm}^{2}$ area was immersed to start the reaction and the progress of reaction was monitored using UV-Vis spectroscopy.

\subsection{Laboratory scale synthesis of functionalized anilines}

$0.5 \mathrm{mmol}$ of nitroaromatic compounds was dissolved in $30 \mathrm{~mL}$ of solvent $\left(\mathrm{H}_{2} \mathrm{O}\right.$ or THF) and $10 \mathrm{~mL}$ of $0.05 \mathrm{M}$ ice-cold $\mathrm{NaBH}_{4}$ solution under stirring condition. The catalytic plate ( $a r e a=$ $2.5 \mathrm{~cm} \times 2.5 \mathrm{~cm}$ ) was then immersed in the above mentioned solution and the stirring was continued at room temperature for at least $3 \mathrm{~h}$ and the reaction was monitored by using TLC. After completion of reaction, the catalytic plate was removed from the reaction mixture. When the water was employed as solvent, the reaction mixture was neutralized using diluted $\mathrm{HCl}$ and the product was extracted using excess ethyl acetate from aqueous medium and the dry sodium sulphate was added to organic extract and filtered. The filtrate was concentrated under reduced pressure to get the product. For the case of THF solvent, after completion of reaction, the solvent was evaporated under reduced pressure and then the water and ethyl acetate was added to the obtained crude and then the usual procedure adopted for water solvent was followed to get the product. NMR analyses were carried out using $\mathrm{CDCl}_{3}$ and the results are presented in supporting information.

\section{Results and Discussion}

\subsection{Characterisation of AuNDs}

AuNDs were prepared using sodium borohydride as a reducing agent in the presence of methionine and base $(\mathrm{KOH})$. In the present investigation, $\mathrm{KOH}$ was found to have a pronounced effect on AuNDs formation, stability and their catalytic activity. In the AuNDs preparation, $\mathrm{KOH}$ concentration was varied as 5,10 and $15 \mathrm{mM}$ and formed AuNDs were named as $\mathrm{M}-\mathrm{Au}-\mathrm{K}_{5}, \mathrm{M}-\mathrm{Au}-\mathrm{K}_{10}$, and $\mathrm{M}-\mathrm{Au}-\mathrm{K}_{15}$, respectively. However, a black precipitate was obtained in the absence and in the presence of 20 $\mathrm{mM}$ and above concentrations of $\mathrm{KOH}$. In the absence of $\mathrm{KOH}$, methionine will exist as zwitterions in aqueous solution and the electrostatic interaction between the methionine molecules led to the aggregation of formed methionine capped AuNDs, whereas high concentration

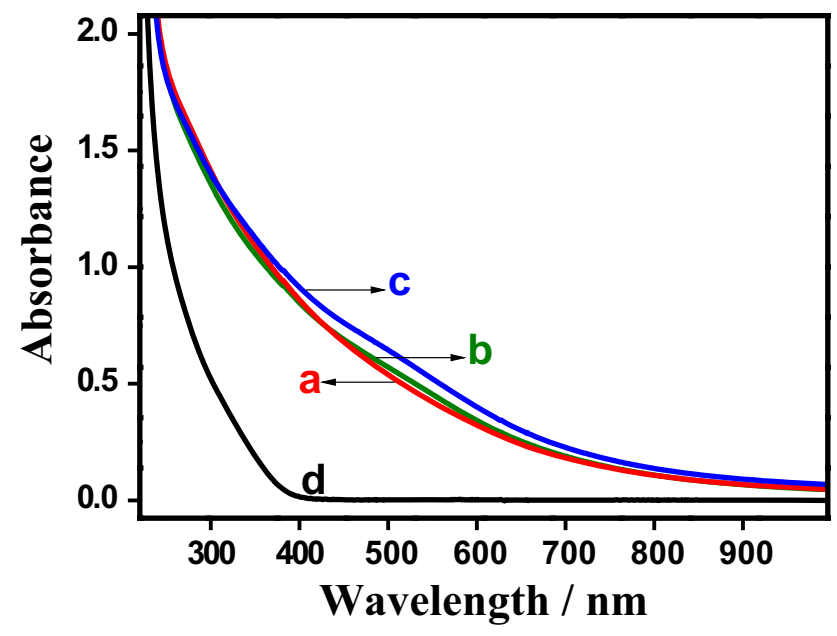

Figure 2. UV-Vis absorption spectra obtained for $\mathrm{M}-\mathrm{Au}-\mathrm{K}_{5}$ (a), M-Au-K 10 (b), M-Au-K 15 (c) NDs and the mixture of methionine, $\mathrm{KOH}$ and $\mathrm{AuCl}_{4}^{-}$(d).

(20 $\mathrm{mM}$ and above) of $\mathrm{KOH}$ creates the unfavourable condition for the stabilisation of AuNDs due to kinetic instability. In this context, optimum concentration (5-15 $\mathrm{mM}$ ) of $\mathrm{KOH}$ has led to the stable formation of AuNDs. In basic condition, methionine will exist in the deprotonated form, i.e., the carboxylic acid group present in the methionine will lose its proton and will form the carboxylate anion at the solution $\mathrm{pH}$ of $\sim 10.5$ and successfully stabilizes the AuNDs through electrostatic stabilization mechanism. Moreover, so formed methionine capped AuNDs were negatively charged in nature due to the deprotonated form of methionine. In order to find the optimum concentration of $\mathrm{Au}$ for catalysis, $\mathrm{AuCl}_{4}^{-}$concentration was varied by keeping the $\mathrm{KOH}$ $(10 \mathrm{mM})$ and methionine $(5 \mathrm{mM})$ concentrations constant. UV-Vis absorption spectra obtained for $\mathrm{M}-\mathrm{Au}-\mathrm{K}_{5}$, $\mathrm{M}-\mathrm{Au}-\mathrm{K}_{10}$, and $\mathrm{M}-\mathrm{Au}-\mathrm{K}_{15}$ NDs are shown in Figure 2. The absorption spectrum obtained for the mixture of methionine, $\mathrm{KOH}$ and $\mathrm{AuCl}_{4}^{-}$has no absorption in the wavelength range of 400 to $550 \mathrm{~nm}$ (Figure 2d), whereas all M-Au-K NDs shows the broad absorption in this region is due to the presence of Au nanostructures. The observed feeble SPR absorbance for AuNDs may be due to the chemisorption of methionine over AuNDs surface. electronic mobility of surface electrons of gold nanoparticles will dramatically decrease when the thiolfunctionalized organic molecules chemisorbed on the $\mathrm{Au}$ NPs surface through the formation of localized Au$\mathrm{S}$ bonds. Since methionine has multifunctional groups, the attachment of other heteroatoms like nitrogen to the $\mathrm{Au}$ surface may cause the disorders in Au-S bond as reported in tiopronin capped gold nanoparticles. ${ }^{6}$ Such disorders in the Au-S bonding arrangement is related to the surface potential fluctuations that preclude collective 
motion of electrons, decreasing the mobility and damping the SPR feature. ${ }^{6,7}$ Similar absorption features were obtained for the AuNPs prepared using various concentrations of $\mathrm{Au}$ precursor (Figure 3). These absorption studies confirm the successful formation of AuNSs in the presence of methionine.

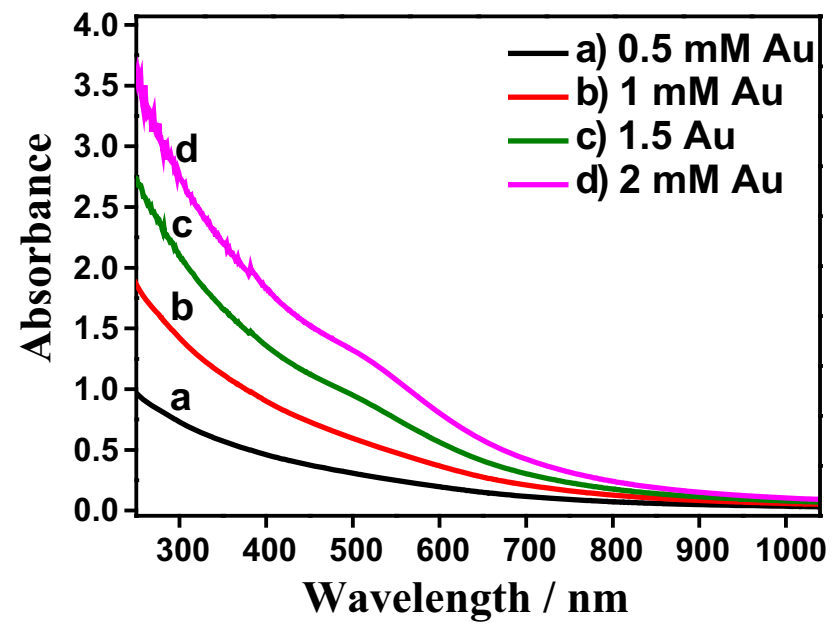

Figure 3. UV-Vis absorption spectra obtained for methionine-capped AuNPs prepared from various concentrations of $\mathrm{AuCl}_{4}^{-}$, where, [Methionine $]=5 \mathrm{mM}$, and $[\mathrm{KOH}]=10 \mathrm{mM}$.
To get a better insight into the reduction of gold ions in the presence of methionine and their chemical environment, XPS spectrum was recorded for $\mathrm{M}-\mathrm{Au}-\mathrm{K}_{10} \mathrm{NDs}$. Figure 4 shows the core-level XPS profile of $\mathrm{Au}, \mathrm{N}, \mathrm{S}$ and $\mathrm{C}$. The $A u 4 f_{7 / 2}$ and $A u 4 f_{5 / 2}$ peaks were observed at the binding energies of 83.3 and $87 \mathrm{eV}$, respectively, with a binding energy difference of $3.7 \mathrm{eV}$. This confirms the successful reduction of $\mathrm{Au}$ ions and the presence of metallic gold in the M-Au-K $\mathrm{K}_{10}$ NDs sample. Compared to the binding energy of bulk metallic gold $\left(\mathrm{Au}^{0}=83.8\right.$ to $\left.84.0 \mathrm{eV}\right),{ }^{8,9}$ the $\mathrm{Au}^{0}$ in the prepared AuNDs sample showed a small shift to lower energy $(83.3 \mathrm{eV})$. The interaction of methionine $(\mathrm{N}$ and $\mathrm{S}$ functional groups) with $\mathrm{Au}$ may slightly shift the $\mathrm{Au}^{0}$ peak. The core-level XPS spectrum of sulphur (S2p region) showed the doublet with a branching ratio of $2: 1$ and the splitting energy difference of $1.2 \mathrm{eV}$. The two peaks observed at 163.3 and $164.5 \mathrm{eV}$ correspond to $\mathrm{S} 2 \mathrm{p}_{3 / 2}$ and $\mathrm{S} 2 \mathrm{p}_{1 / 2}$, respectively, is the characteristic XPS signal of thioether sulphur. Another peak observed at $162 \mathrm{eV}$ is due to the interaction of sulphur with $\mathrm{Au} .{ }^{10}$ The core-level XPS data of nitrogen shows two peaks at 399.5 and $401.5 \mathrm{eV}$. The peak at $399.5 \mathrm{eV}$ corresponds to neutral state nitrogen in methionine capped AuNDs and the peak at $401.5 \mathrm{eV}$ corresponds to the
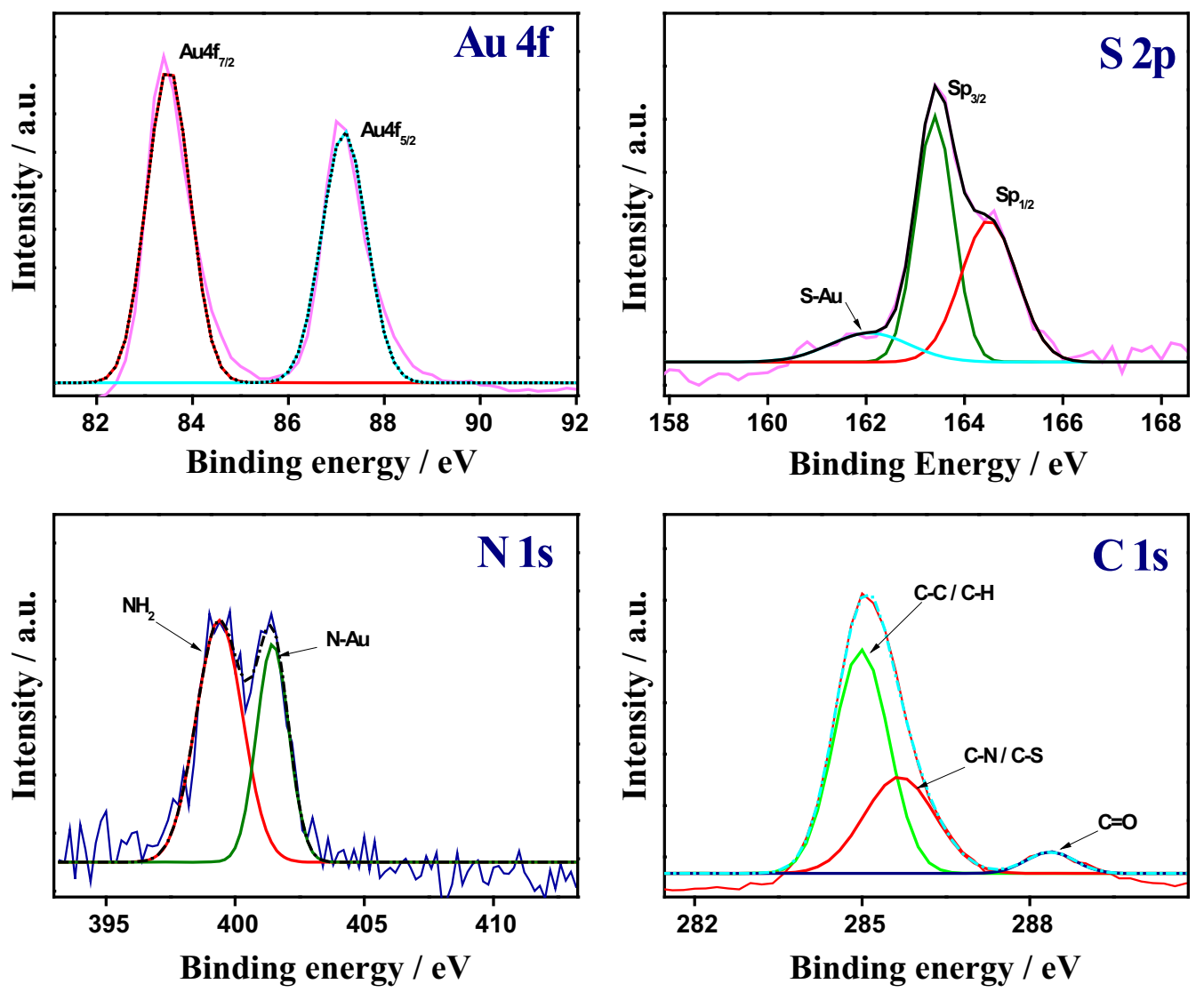

Figure 4. Core level XPS data obtained for the constituent elements of Meth-Au-K $\mathrm{K}_{10}$. 
interaction of nitrogen atom to Au. Generally, in the N 1s regime, the observed peak at higher binding energy $(401.5 \mathrm{eV})$ is attributed to the positively charged amine group whereas in the present experimental condition, as the solution $\mathrm{pH}$ is around 10.5 , there is no possibility for amine being protonated. On the other hand, the Au4f signals shifted to the lower binding energies in comparison to pure $\mathrm{Au}(84 \mathrm{eV})$. A similar negative shift in binding energy was already reported in $\mathrm{Au}$ and $\mathrm{Pt}$ NPs bonded with amines. ${ }^{11,12}$ Hence, the higher binding energy $(401.5 \mathrm{eV})$ in $\mathrm{N} 1 \mathrm{~s}$ region can be accounted for the interaction of amine groups with $\mathrm{Au}$. The XPS spectrum of $\mathrm{C} 1 \mathrm{~s}$ region was fitted to three components that correspond to the carbon atom bonded to carbon or hydrogen $(285 \mathrm{eV})$, carbon atom bonded to sulphur and/or oxygen $(285.6 \mathrm{eV})$ and carboxylic acid group $(285.5 \mathrm{eV})$ present in the methionine molecule. From the XPS results, it is confirmed that prepared AuNDs sample contains methionine and metallic state Au. Further, it confirms that the formed AuNDs were stabilized by both nitrogen and sulphur functional groups present in the methionine.

To evaluate the actual size and shape of M-Au-K NDs, the HRTEM images were recorded (Figure 5). AuNDs showed spherical particles with less than $5 \mathrm{~nm}$ in size. The concentration of $\mathrm{KOH}$ employed in the preparation of AuNDs was found to affect the particle size; $\mathrm{M}-\mathrm{Au}-\mathrm{K}_{5}$ and $\mathrm{M}-\mathrm{Au}-\mathrm{K}_{15}$ NDs had average particle size of $3.7 \mathrm{~nm}$ and $\mathrm{M}-\mathrm{Au}-\mathrm{K}_{10}$ having average particle size of $2.6 \mathrm{~nm}$. The histogram of $\mathrm{M}-\mathrm{Au}-\mathrm{K}_{5}$ and $\mathrm{M}-\mathrm{Au}-\mathrm{K}_{15}$ showed that size of the majority of the AuNDs formed is around 4 $\mathrm{nm}$ and the histogram of $\mathrm{M}-\mathrm{Au}-\mathrm{K}_{10}$ shows that size of most of the particles is around $3 \mathrm{~nm}$. Hence, $10 \mathrm{mM}$ $\mathrm{KOH}$ favours the formation of smaller size AuNDs in the presence of methionine. Figure 6 shows the HRTEM images obtained for AuNPs prepared using $0.5 \mathrm{mM}$ and $2 \mathrm{mM} \mathrm{AuCl}_{4}^{-}$concentrations in the presence of $5 \mathrm{mM}$ methionine and $10 \mathrm{mM} \mathrm{KOH}$. Less than $5 \mathrm{~nm}$ AuNDs were formed when the Au concentration was $0.5 \mathrm{mM}$, whereas, $10 \mathrm{~nm}$ anisotropic AuNPs were formed with 2 $\mathrm{mM}$ Au precursor. In addition, ring patterns observed in the SAED analysis confirm the polycrystalline nature of AuNDs. XRD analyses were carried out to study the crystalline nature of the prepared AuNDs. Figure 7 shows the XRD pattern obtained for the $\mathrm{M}-\mathrm{Au}-\mathrm{K}_{5}$, $\mathrm{M}-\mathrm{Au}-\mathrm{K}_{10}$ and $\mathrm{M}-\mathrm{Au}-\mathrm{K}_{15}$. Sharp diffraction peaks of XRD data confirm the formation of highly crystalline AuNDs. The diffraction peaks obtained for AuNDs at $2 \theta$
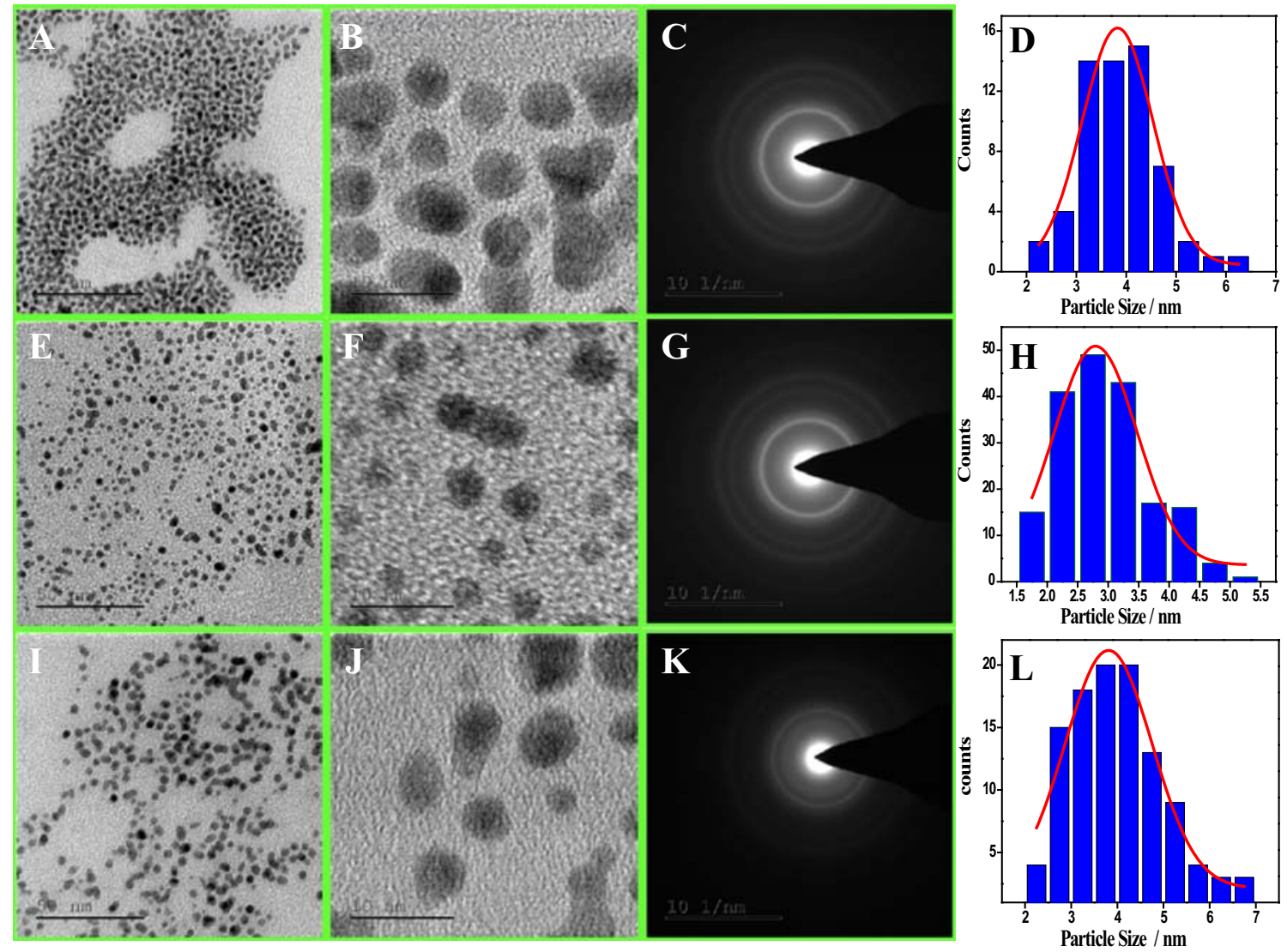

Figure 5. HRTEM images, SAED pattern and particle size distribution histogram of $M-A u-K_{5}(\mathbf{A}-\mathbf{D})$, $\mathrm{M}-\mathrm{Au}-\mathrm{K}_{10}(\mathbf{E}-\mathbf{H}), \mathrm{M}-\mathrm{Au}-\mathrm{K}_{15}(\mathbf{I}-\mathbf{L})$ NDs. 


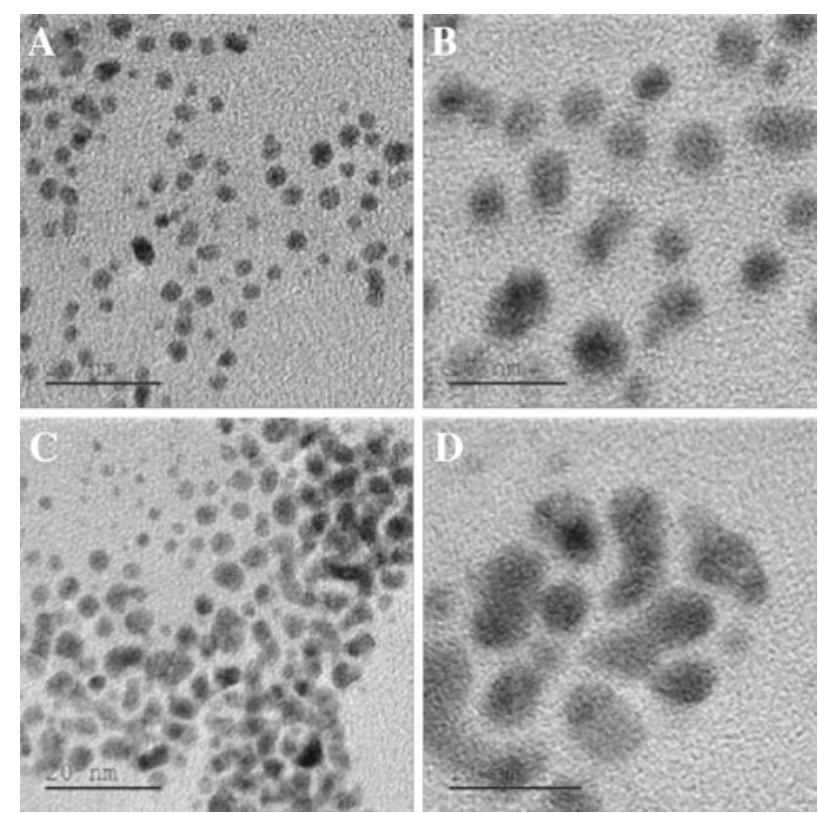

Figure 6. HRTEM images obtained for AuNPs prepared using 0.5 mM Au (A-B) and $2 \mathrm{mM} \mathrm{Au}(\mathbf{C}-\mathbf{D})$.

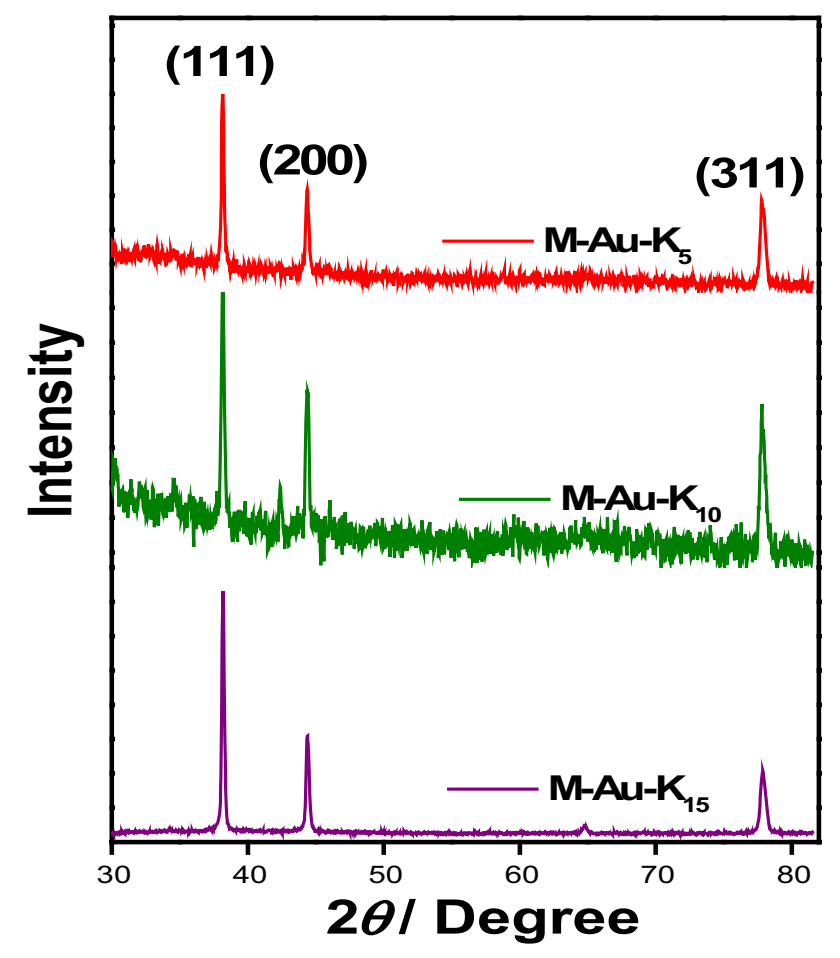

Figure 7. XRD pattern obtained for M-Au-K NDs.

values of $38.2^{\circ}, 44.3^{\circ}$ and $77.8^{\circ}$ are assigned to the (111), (200) and (311) crystal planes of face-centred cubic $\mathrm{Au}$ crystals, respectively. Moreover, high index facets could enhance the catalytic activity of nanomaterials as observed by many researchers. ${ }^{13,14}$ Hence, the presence of high intensity (311) plane is the key factor for enhanced catalysis. The intensity ratios of $(311) /(111)$ crystallizations are $0.29,0.70$ and 0.56 for $\mathrm{M}-\mathrm{Au}-\mathrm{K}_{5}$, $\mathrm{M}-\mathrm{Au}-\mathrm{K}_{10}$ and $\mathrm{M}-\mathrm{Au}-\mathrm{K}_{15}$, respectively. Therefore, as observed in catalytic tests, the higher catalytic activity of $\mathrm{M}-\mathrm{Au}-\mathrm{K}_{10}$ is attributed to a higher ratio of (311)/(111).

\subsection{Catalytic reduction of nitroaromatics}

To test the catalytic activity of the prepared AuNDs, reduction of 4-Nitrophenol (4-NP) in the presence of $\mathrm{NaBH}_{4}$ was adopted as the model reaction. UVVis absorption spectroscopy was used to monitor the progress of catalytic reduction of 4-NP. Addition of $\mathrm{NaBH}_{4}$ to 4-NP solution readily produces the 4-nitrophenolate ion, which showed the strong absorption at $400 \mathrm{~nm}$. Without a catalyst, the peak around 400 $\mathrm{nm}$ remained unaltered for a long time indicating that there was no reduction reaction. Whereas, in the presence of a catalyst (AuNDs), a successive decrease in the intensity of absorption peak at $400 \mathrm{~nm}$ was observed with time and simultaneously, a new peak started growing at $302 \mathrm{~nm}$, corresponding to 4-aminophenol (Figure $\mathrm{S} 1$ in Supplementary Information), which confirms the conversion of nitro to the amine. The mechanistic pathway for the reduction of aromatic nitrocompounds to the corresponding aromatic amine compounds has been reported to follow either a direct route or a condensation route. ${ }^{15}$ In the most possible direct pathway, both $\mathrm{BH}_{4}^{-}$ions and nitroaomatics would get adsorbed on the catalyst surface first, where $\mathrm{BH}_{4}^{-}$ions will act as the hydrogen source, to accomplish the hydrogenation of nitroaomatics on the surface of the metal NPs. Hence, $\mathrm{BH}_{4}^{-}$ions could charge the metal NPs surface and the charged metal NPs could act as the electron source. ${ }^{16}$ The aromatic nitrocompound is first reduced to the nitroso compound and then quickly to the corresponding hydroxylamine compound. The hydroxylamine compound was finally reduced to the aromatic amine. ${ }^{17}$ As the concentration of 4-NP is very low when compared to $\mathrm{NaBH}_{4}$, the reaction follows the pseudo-first-order kinetics and the rate constant $(k)$ values are calculated from the slope of $\ln (\mathrm{A})$ versus time. In the catalytic reduction of 4-NP in, the presence of $\mathrm{NaBH}_{4}$, complete reduction of 4-NP was observed at 180 and $200 \mathrm{~s}$ at $\mathrm{M}-\mathrm{Au}-\mathrm{K}_{5}$ and $\mathrm{M}-\mathrm{Au}-\mathrm{K}_{15}$ catalysts respectively, whereas $\mathrm{M}-\mathrm{Au}-\mathrm{K}_{10}$ took only $120 \mathrm{~s}$ for the same. The rate constants obtained for $\mathrm{M}-\mathrm{Au}-\mathrm{K}_{5}, \mathrm{M}-\mathrm{Au}-\mathrm{K}_{10}$, and $\mathrm{M}-\mathrm{Au}-\mathrm{K}_{15}$ NDs catalysts for the reduction of 4-NP are 1.599 $\times 10^{-2} \mathrm{~s}^{-1}, 2.982 \times 10^{-2} \mathrm{~s}^{-1}$ and $1.518 \times 10^{-2} \mathrm{~s}^{-1}$, respectively, and the $\mathrm{M}-\mathrm{Au}-\mathrm{K}_{10} \mathrm{NDs}$ was found to have a better catalytic activity compared to other two AuNDs. Table 1 compares the catalytic performance of the present AuNDs with reported results towards the reduction of 4-NP. The TOF values calculated for 
Table 1. Comparison of catalytic activity of present AuNDs with reported results.

\begin{tabular}{|c|c|c|c|c|}
\hline Catalyst material & $\begin{array}{l}\text { Catalyst } \\
(\mathrm{mol} \%)\end{array}$ & $\begin{array}{l}\mathrm{NaBH}_{4} \\
\text { equivalent }\end{array}$ & $k_{\mathrm{app}}\left(\mathrm{s}^{-1}\right)$ & References \\
\hline 2D graphene oxide $/ \mathrm{SiO}_{2}-\mathrm{Au}$ & - & - & $17 \times 10^{-3}$ & 18 \\
\hline CTAB-Au NPs & 1.25 & 500 & $6.1 \times 10^{-3}$ & 19 \\
\hline Au@DHBC NPs & 0.5 & 300 & $9.5 \times 10^{-3}$ & 20 \\
\hline PGMA@PAH@Au NPs & 3.2 & 400 & - & 21 \\
\hline Methyl-imidazolium-based ionic polymer-AuNPs & 20 & 88 & $3.3 \times 10^{-2}$ & 22 \\
\hline PAMAM-AuNPs & 0.10 & 100 & $7.91 \times 10^{-3}$ & 23 \\
\hline PPI-AuNPs & 0.10 & 100 & $1.47 \times 10^{-2}$ & 24 \\
\hline rCD-AuNPs & $5.2 \times 10^{-5}$ & 75 & $9.75 \times 10^{-4}$ & 25 \\
\hline $\mathrm{CeO}_{2}$-AuNPs & - & 1333 & $1.28 \times 10^{-2}$ & 26 \\
\hline Au@PVP & 1.56 & 147 & $1.02 \times 10^{-2}$ & 27 \\
\hline Cyclodextrin-AuNPs & 17.6 & 44 & $4.65 \times 10^{-3}$ & 28 \\
\hline Polyaniline-AuNPs & 17.6 & 44 & $11.7 \times 10^{-3}$ & 29 \\
\hline $\mathbf{M}-\mathbf{A u}-\mathbf{K}_{\mathbf{1 0}} \mathbf{N D s}$ & 12.5 & 125 & $2.98 \times 10^{-2}$ & Present catalyst \\
\hline
\end{tabular}
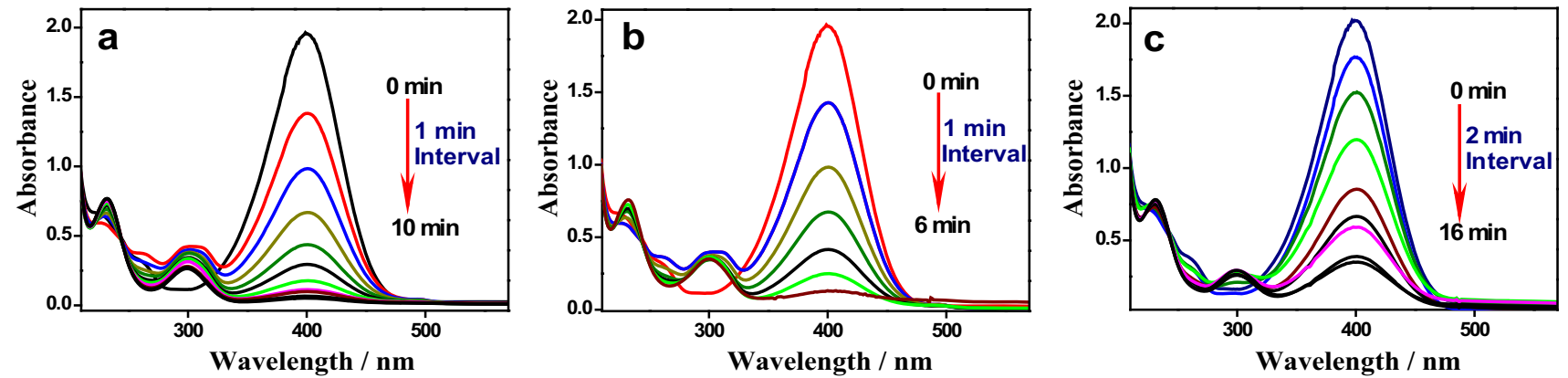

Figure 8. Catalytic reduction of 4-NP in the presence of $\mathrm{NaBH}_{4}$ using catalytic plates prepared by $\mathrm{M}-\mathrm{Au}-\mathrm{K}_{5}(\mathbf{a}), \mathrm{M}-\mathrm{Au}-\mathrm{K}_{10}$ (b) and $\mathrm{M}-\mathrm{Au}-\mathrm{K}_{15}$ (c) NDs.

the reduction of 4-NP using $\mathrm{M}-\mathrm{Au}-\mathrm{K}_{5}, \mathrm{M}-\mathrm{Au}-\mathrm{K}_{10}$ and $\mathrm{M}-\mathrm{Au}-\mathrm{K}_{15}$ NDs colloids are $0.044,0.066$ and $0.040 \mathrm{~s}^{-1}$, respectively.

To find the optimum concentration of Au for catalysis, catalytic reduction studies were also performed for the AuNPs prepared using various concentration of $\mathrm{Au}(0.5,1,1.5$ and $2 \mathrm{mM}$ ) (Figure S2). Among the different $\mathrm{Au}$ concentrations, $1 \mathrm{mM} \mathrm{Au}$ was found to be the optimum concentration of Au for catalysis and no increment in catalytic activity was observed at the higher Au concentrations (>1 mM). However, in laboratory scale reactions, removal of such homogeneous catalyst (AuNDs colloids) from the reaction mixture and reusability of the catalyst remains a challenge. Hence, to overcome these issues, catalytic plates were designed using the so formed AuNDs over glass plates with the aid of PADA and successfully applied for catalytic reductions. To understand the catalytic ability of $\mathrm{M}-\mathrm{Au}-\mathrm{K}$ NDs self-assembled on PADA modified glass plates, $0.8 \times 1.5 \mathrm{~cm}^{2}$ (area $\left.=1.2 \mathrm{~cm}^{2}\right)$ catalytic plates were subjected to catalytic tests (Figure 8 ). Protocols for the preparation of catalytic plates are described in the Section 2. PADA is positively charged and the prepared AuNDs are negatively charged in nature, hence, it is obvious that when the PADA modified glass plate was dipped in AuNDs solution, AuNDs self-assembled over the PADA through electrostatic interaction. Selfassembly of AuNDs on to the PADA modified glass plates was confirmed by recording AFM images (Figure S3). The AFM images of PADA modified glass plate showed the smooth and plain surface whereas, AuNDs self-assembled on PADA modified glass plates clearly showed the dense decoration of spherical AuNDs over PADA surface. Among the three catalytic plates prepared using $\mathrm{M}-\mathrm{Au}-\mathrm{K}_{5}, \mathrm{M}-\mathrm{Au}-\mathrm{K}_{10}$ and $\mathrm{M}-\mathrm{Au}-\mathrm{K}_{15}$ NDs, best catalytic activity was observed at $\mathrm{M}-\mathrm{Au}-\mathrm{K}_{10}$ towards the reduction of 4-NP (Figure 8b) and the catalytic plate was reused for five consecutive catalytic cycles without considerable loss in activity (Figure S4 in SI). Hence, the M-Au-K $\mathrm{K}_{10}$ NDs self-assembled on the PADA modified large area $(2.5 \times 2.5 \mathrm{~cm})$ glass plate was chosen to carry out the laboratory scale $(0.5 \mathrm{mmol}$ batch $)$ 
reductions of different nitroaromatic compounds into their corresponding amino compounds. When the catalytic performance of as-synthesized colloids of AuNDs and AuNDs self-assembled onto catalytic plates were compared, the catalytic plates showed lower catalytic activity. This may be due to the low amount of AuNDs loading in the PADA film when compared to the amount of $\mathrm{Au}$ in as-synthesized AuNDs colloids.

Generally, the reduction of nitroaromatics into their corresponding amines was accomplished under harsh conditions including strong acids and various metals like lead and tin. These reactions suffer from severity present in safety and environmental issues associated with their applicability in scale-up processes. ${ }^{30}$ To overcome these issues, several modified protocols were reported in recent years and among the various catalytic systems, noble metal NPs catalysed reduction of nitroaromatics have received great interest due to their excellent activity. Especially, catalytic AuNPs decorated membranes are considered to be advantageous for the reduction of nitroaromatics, in the presence of $\mathrm{NaBH}_{4} \cdot{ }^{31}$ Selective reduction of nitro groups in the presence of other reducible functional groups is the most important reaction to synthesis functionalized anilines as industrial intermediates for a variety of specific and fine chemicals. ${ }^{32}$ Conventional Pt group of catalysts hydrogenate both olefinic and carbonyl functions while reducing the nitro group in the presence of $\mathrm{H}_{2}$. Hence, in the search of catalyst for the purpose of selective reduction of nitroaromatics in the presence of olefinic bond, reduction of nitro-substituted chalcones were examined and it was found that the present AuNDs catalyst film selectively hydrogenated the nitro groups in the presence of olefinic double bond at room temperature and also reduced the carbonyl group of chalcone together with nitro group (Table 1 ( $2 \mathrm{e}$ and $2 \mathrm{f}$ )), while leaving the olefinic double bond unaltered. Hence, the present catalyst film selectively reduces the carbonyl group of chalcones ( $\alpha, \beta$-unsaturated carbonyl system) without affecting olefinic double bond to produce allylic alcohols that are recognized as important intermediates in Agrochemistry, Pharmaceutical and Fragrance Chemistry. Such selectivity is ascribed to the formation of charged hydrogen species $\left(\mathrm{H}^{+}\right.$and $\left.\mathrm{H}^{-}\right)$on the metal catalyst surfaces. These charged hydrogen species are active towards the reduction of polar groups like nitro and keto but they are unable to reduce non-polar olefinic bonds. In addition to this, nitro group reductions were accomplished successfully in the presence of carboxylic acid, chloro, methoxy, hydroxyl and amine groups. Table 2 shows the reduction of different nitro compounds using the $\mathrm{M}-\mathrm{Au}-\mathrm{K}_{10}$ catalyst. Product formation was confirmed by recording the ${ }^{1} \mathrm{H}$ NMR and
Table 2. Reduction of various nitroaromatic compounds.

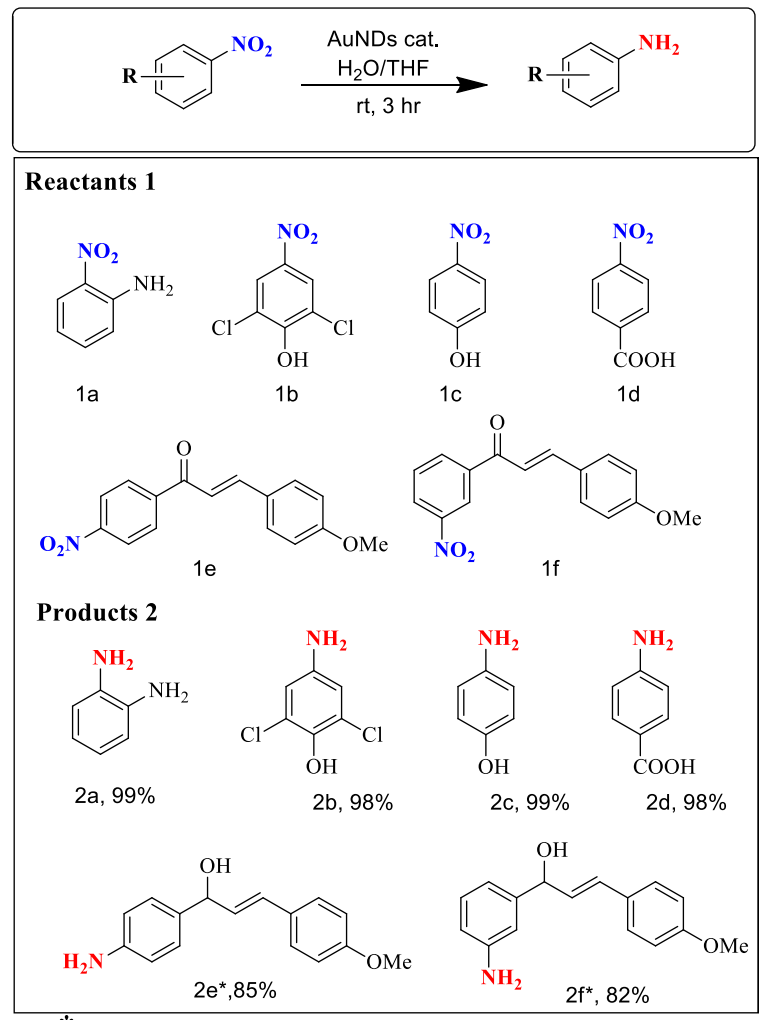

* THF was used as solvent

${ }^{13}$ C NMR spectra (Figure S5-S16 in Supplementary Information).

\section{Conclusions}

A facile, single-step preparation of methionine-capped AuNDs and their successful self-assembly on PADAmodified glass plate was demonstrated for nitroaromatics reduction application. Moreover, it was observed that it is very easy to remove the present catalytic plates from the reaction mixture and the catalytic plates are stable for two months at laboratory conditions. Therefore, these catalytic plates have the advantages of homogeneous catalysts even though these are heterogeneous catalysts. Further, these catalytic plates would serve as excellent alternative for noble metal NPs-decorated metal oxide and other heterogeneous nanocatalysts in terms recovery and reusability of catalyst.

\section{Supplementary Information (SI)}

Catalytic test reactions of 4-NP reductions in the presence of AuNDs catalyst, recycle test, ${ }^{1} \mathrm{H}$ NMR and ${ }^{13} \mathrm{C}$ NMR data of reduced products obtained in laboratory scale synthesis (Table 2) and Figures S1-S16 are given in the Supplementary Information, available at www.ias.ac.in/chemsci. 


\section{Acknowledgements}

RR acknowledges the financial support received from the CSIR-Emeritus Scientist Scheme, New Delhi. PV is the recipient of Senior Research Fellowship under UGC-BSR scheme.

\section{References}

1. Thomas J M and Thomas W J 1997 (Eds.) In Principles and Practice of Heterogeneous Catalysis (VCH: Weinheim)

2. An K and Somorjai G A 2015 Nanocatalysis I: synthesis of metal and bimetallic nanoparticles and porous oxides and their catalytic reaction studies Catal. Lett. 145233

3. Daniel M-C and Astruc D 2004 Gold nanoparticles: assembly, supramolecular chemistry, quantumsize-related properties, and applications toward biology, catalysis, and nanotechnology Chem. Rev. 104293

4. Tamiolakis I, Fountoulaki S, Vordos N, Lykakisb I N and Armatas G S 2013 Mesoporous $\mathrm{Au}-\mathrm{TiO}_{2}$ Nanoparticle assemblies as efficient catalysts for the chemoselective reduction of nitrocompounds J. Mater. Chem. A 1 14311

5. Rathore P S, Patidar R, Shripathic T and Thakore S 2015 Magnetically separable core-shell iron oxide@nickel nanoparticles as high-performance recyclable catalysts for chemoselective reduction of nitroaromatics Catal. Sci. Technol. 5286

6. Guerrero E, Munoz-Marquez M A, Garcia M A, Crespo P, Fernandez-Pinel E, Hernando A and Fernandez A 2008 Surface plasmon resonance and magnetism of thiol-capped gold nanoparticles Nanotechnology 19 175701

7. Templeton A C, Chen S, Gross S M and Murray R W 1999 Water-soluble isolable gold clusters protected by tiopronin and coenzyme A monolayers Langmuir 1566

8. Bourg M-C, Badia A and Lennox R B 2000 Gold-sulfur bonding in 2D and 3D self-assembled monolayers: XPS characterization J. Phys. Chem. B 1046562

9. Gaur S, Miller J T, Stellwagen D, Sanampudi A, Kumar C S S R and Spivey J J 2012 Synthesis, characterization, and testing of supported Au catalysts prepared from atomically-tailored $\mathrm{Au}_{38}(\mathrm{SC} 12 \mathrm{H} 25) 24$ clusters Phys. Chem. Chem. Phys. 141627

10. Angelova P, Solel, E, Parvari G, Turchanin A, Botoshansky M, Gölzhauser A and Keinan E 2013 Chemisorbed monolayers of corannulene penta-thioethers on gold Langmuir 292217

11. Tseng R J, Baker C O, Shedd B, Huang J, Kaner R B, Ouyang J and Yang Y 2007 Charge transfer effect in the polyaniline-gold nanoparticle memory system Appl. Phys. Lett. 90053101

12. Qiu L, Liu F, Zhao L, Yang W and Yao J 2006 Evidence of a unique electron donor-acceptor property for platinum nanoparticles as studied by XPS Langmuir 224480

13. Viswanathan P and Ramaraj R 2017 Preparation of polyelectrolyte-stabilized silver nanoparticles for catalytic applications Polym. Int. 66342

14. Tian N, Zhou Z-Y, Sun S-G, Ding Y and Wang Z L 2007 Synthesis of tetrahexahedral platinum nanocrystals with high-index facets and high electro-oxidation activity $\mathrm{Sci}$ ence 316732

15. Viswanathan P and Ramaraj R 2016 Polyelectrolyte assisted synthesis and enhanced catalysis of silver nanoparticles: electrocatalytic reduction of hydrogen peroxide and catalytic reduction of 4-nitroaniline J. Mol. Catal. A Chem. $\mathbf{4 2 4} 128$

16. Henglein A and Lilie J 1981 Storage of electrons in aqueous solution: the rates of chemical charging and discharging the colloidal silver microelectrode J. Am. Chem. Soc. 1031059

17. Chiu C-Y, Chung P-J, Lao K-U, Liao C-W and Huang M H 2012 Facet-dependent catalytic activity of gold nanocubes, octahedra, and rhombic dodecahedra toward 4-nitroaniline reduction J. Phys. Chem. C 11623757

18. Zhu C, Han L, Hu P and Dong S 2012 In situ loading of well-dispersed gold nanoparticles on two-dimensional graphene oxide $/ \mathrm{SiO}_{2}$ composite nanosheets and their catalytic properties Nanoscale 41641

19. Fenger R, Fertitta E, Kirmse H, Thunemann A F and Rademann K 2012 Size dependent catalysis with CTAB-stabilized gold nanoparticles Phys. Chem. Chem. Phys. 149343

20. Seo E, Kim J, Hong Y, Kim Y S, Lee D and Kim B S 2013 Double hydrophilic block copolymer templated Au nanoparticles with enhanced catalytic activity toward nitroarene reduction J. Phys. Chem. C 11711686

21. Li M and Chen G 2013 Revisiting catalytic model reaction P-nitrophenol/ $\mathrm{NaBH}_{4}$ using metallic nanoparticles coated on polymeric spheres Nanoscale 511919

22. Biondi I, Laurenczy G and Dyson P J 2011 Synthesis of gold nanoparticle catalysts based on a new water-soluble ionic polymer Inorg. Chem. 508038

23. Esumi K, Miyamoto K and Yoshimura T 2003 Morphological change of gold-dendrimer nanocomposites by laser irradiation J. Colloid Interface Sci. 268501

24. Hayakawa K, Yoshimura T and Esumi K 2003 Preparation of gold-dendrimer nanocomposites by laser irradiation and their catalytic reduction of 4-nitrophenol Langmuir 195517

25. Wang X, Long Y, Wang Q, Zhang H, Huang X, Zhu R, Teng P, Liang L and Zheng H Z 2013 Reduced state carbon dots as both reductant and stabilizer for the synthesis of gold nanoparticles Carbon 64499

26. Fan C M, Zhang L F, Wang S S, Wang D H, Lu L Q and Xu A W 2012 Novel $\mathrm{CeO}_{2}$ yolk-shell structures loaded with tiny Au nanoparticles for superior catalytic reduction of $p$-nitrophenol Nanoscale 46835

27. Xiao C, Chen S, Zhang L, Zhou S and Wu W 2012 Onepot synthesis of responsive catalytic Au@PVP hybrid nanogels Chem. Commun. 4811751

28. Huang T, Meng F and Qi L 2009 Facile synthesis and one-dimensional assembly of cyclodextrin-capped gold nanoparticles and their applications in catalysis and surface-enhanced raman scattering J. Phys. Chem. C 113 13636

29. Han J, Li L and Guo R 2010 Novel approach to controllable synthesis of gold nanoparticles supported on polyaniline nanofibers Macromolecules 4310636

30. Kelly S M and Lipshutz B H 2014 Chemoselective reductions of nitroaromatics in water at room temperature $\mathrm{Org}$. Lett. 1698 
31. Dotzauer D M, Bhattacharjee S, Wen Y and Bruening M 2009 Nanoparticle-containing membranes for the catalytic reduction of nitroaromatic compounds Langmuir 251865
32. Blaser H-U, Siegrist U and Steiner H 2001 In Aromatic Nitro Compounds: Fine Chemicals through Heterogeneous Catalysis (Wiley-VCH: Weinheim) p. 389 